Opinion

\title{
Expert Opinion on the Management of Non-Alcoholic Fatty Liver Disease (NAFLD) in the Middle East with a Focus on the Use of Silymarin
}

\author{
Ahmed Hashem ${ }^{1, *}$, Yogesh Shastri ${ }^{2}$, Malfi Al Otaibi ${ }^{3}$, Elwin Buchel ${ }^{4}$, Hussam Saleh ${ }^{5}$, Reyaz Ahmad ${ }^{6}$, \\ Hamouda Ahmed ${ }^{7}$, Fateh Al Idris ${ }^{3}$, Saleh Ahmed ${ }^{3}$, Mohamed Guda ${ }^{8}$ and Anton Gillessen ${ }^{9}$ \\ Endemic Medicine Department, Cairo University—Saudi German Hospital, Jeddah 23521, Saudi Arabia \\ NMC Specialty Hospital, Abu Dhabi 6222, United Arab Emirates; drshastri@gmail.com \\ Sulaiman Al Habib Hospital, Olaya Medical Complex, Riyadh 11643, Saudi Arabia; \\ malfi999@hotmail.com (M.A.O.); fatidr@yahoo.com (F.A.I.); salahelshafie@eircom.net (S.A.) \\ 4 Burjeel Hospital, Abu Dhabi 7400, United Arab Emirates; elwinbuchel@yahoo.com \\ 5 Dr Sulaiman Al Habib Hospital, Dubai 505005, United Arab Emirates; samboo@hotmail.com \\ Prime Hospital, Dubai 125035, United Arab Emirates; reyazahmadhafiz@gmail.com \\ Al Salama Hospital, Abu Dhabi 46266, United Arab Emirates; aharnaout@zu.edu.eg \\ Mouwasat Hospital, Dammam 31411, Saudi Arabia; mfguda30@yahoo.com \\ Herz-Jesu-Krankenhaus Muenster, 48165 Muenster, Germany; anton.gillessen@hjk-muenster.de \\ Correspondence: endoscopy1.jed@sghgroup.net; Tel.: +966-506625155
}

Citation: Hashem, A.; Shastri, Y.; Al Otaibi, M.; Buchel, E.; Saleh, H.; Ahmad, R.; Ahmed, H.; Al Idris, F.; Ahmed, S.; Guda, M.; et al. Expert Opinion on the Management of Non-Alcoholic Fatty Liver Disease (NAFLD) in the Middle East with a Focus on the Use of Silymarin. Gastroenterol. Insights 2021, 12, 155-165. https://doi.org/10.3390/ gastroent12020014

Academic Editor: Yoshio Sumida

Received: 28 January 2021

Accepted: 9 March 2021

Published: 1 April 2021

Publisher's Note: MDPI stays neutral with regard to jurisdictional claims in published maps and institutional affiliations.

Copyright: (c) 2021 by the authors. Licensee MDPI, Basel, Switzerland. This article is an open access article distributed under the terms and conditions of the Creative Commons Attribution (CC BY) license (https:// creativecommons.org/licenses/by/ $4.0 /)$.

Abstract: Non-alcoholic fatty disease (NAFLD) is amongst the leading causes of chronic liver disease worldwide. The prevalence of NAFLD in the Middle East is $32 \%$, similar to that observed worldwide. The clinicians in this region face several challenges in diagnosing and treating patients with NAFLD. Additionally, there are no national or regional guidelines to address the concerns faced with current treatment options. Silymarin, derived from milk thistle, provides a rational and clinically proven approach to hepatoprotection. This article focuses on addressing regional diagnostic challenges and provides clear guidance and potential solutions for the use of Silymarin in the treatment of NAFLD in the Middle East. Both clinical and preclinical studies have highlighted the efficiency of Silymarin in managing NAFLD by reducing liver disease progression and improving patient symptoms and quality of life, alongside being safe and well tolerated. An expert panel of professionals from the Middle East convened to establish a set of regional-specific diagnostics. A consensus was established to aid general physicians to address the diagnostic challenges in the region. In conclusion, Silymarin can be considered beneficial in treating NAFLD and should be initiated as early as possible and continued as long as necessary.

Keywords: non-alcoholic fatty liver disease; milk thistle; silymarin; silybin; diagnostic challenges; treatment challenges; Middle East

\section{Introduction}

Non-alcoholic fatty liver disease (NAFLD) is one of the leading causes of chronic liver disease in the world [1-4]. It includes a histological continuum of non-alcoholic fatty liver (NAFL), non-alcoholic steatohepatitis (NASH), fibrosis, cirrhosis, and hepatocellular carcinoma (HCC), which can be differentiated by liver biopsy [2,3]. A meta-analysis study indicated that $25 \%$ of the adult population worldwide had NAFLD, with incidence of NASH in up to one-third of them [1]. Men are at a higher risk of developing NAFLD and NASH compared to women [5,6]. It is notable that Hispanics (45-58\%) are more prone to developing NASH whereas African Americans (24-35\%) have a lower prevalence in terms of ethnicity $[5,7,8]$. The scenario of increased NAFLD prevalence is also seen in children increasing with age, ranging from $0.7 \%$ for ages $2-4$, up to $17.3 \%$ for ages $15-19$ years [9]. NASH is associated with increased liver-related mortality and hepatocellular carcinoma, 
even in the absence of cirrhosis, and is predicted to become a rising indication for liver transplantation by 2020 [2,10-14].

As noted previously, there is strong evidence suggesting that components of metabolic syndrome (MetS) are highly prevalent in patients with NAFLD and NASH $(41 \%$ and $71 \%$, respectively) [1]. Patients with NAFLD usually present as obese, with insulin resistance and / or type 2 diabetes mellitus (T2DM), dyslipidaemia, and hypertension-all of these are risk factors for cardiovascular diseases (CVDs) $[15,16]$. Owing to the similarity in risk factors between NAFLD and CVDs, cardiac-related death has thus become one of the leading causes of death in NAFLD patients [17-19]. The overall mortality is 34 times higher in patients with NAFLD with at least 1 MetS component than those without any adjacent condition [20]. International guidelines such as European Association for the Study of the Liver (EASL) and American Association for the Study of Liver Diseases (AASLD) recommend lifestyle modifications and diet control to achieve weight reduction and insulin sensitivity in NAFLD. However, the long-term benefit of these modalities is debatable, mainly due to lack of patient compliance. Guidelines suggest the use of pioglitazone and vitamin E, but with strong limitations and as off-label treatments [4,21]. Clinical studies in NAFLD confirm that silymarin can positively affect liver disease progression and improve patients' symptomatology, clinical conditions, and quality of life [22-24].

There is scarce data on the epidemiology of NAFLD in the Middle East [25]. The prevalence of NAFLD in the region is high and is projected to rise over 30\% in the coming years due to various driving factors such as obesity and type 2 diabetes [1,26]. Due to limited therapeutic options available to manage NAFLD patients in this region, clinicians face several challenges in diagnosis and treatment, affecting patient management on the whole. Although EASL/AASLD provides guidelines for clinical management of NAFLD, there are no national or regional guidelines to address the concerns faced with regionavailable treatment options. Silymarin provides a rational approach to hepatoprotection. This article aims to address the defined regional challenges and provide clear guidance and potential solutions for the use of silymarin in the Middle East in the treatment of NAFLD.

\section{Materials and Methods}

This article is based on the one-day advisory board meeting of expert professionals that convened in Dubai, United Arab Emirates (UAE) in June 2019. The panel of experts reviewed literature on the use of silymarin in treating NAFLD, and debated about its role, specifically in the Middle East practice. Several authors were acquainted with the used literature in personal work and presentations. Full-text articles of the references used to develop this manuscript were electronically sourced or via direct contact with the authors. An in-depth search on Google Scholar, Medline, and PubMed was conducted using the keywords "non-alcoholic fatty liver disease" and "non-alcoholic steatohepatitis", in addition to "prevalence and risk factors for NAFLD" and "silymarin", with special emphasis on the Middle East countries. Overall, selection of papers was based on relevance of active compound (silymarin), relevance of therapeutic area, and experimental setting (clinical data for effectiveness, in vivo/in vitro setting to support mechanism of action of compound).

\section{Results}

\subsection{Burden of NAFLD in the Middle East}

Non-alcoholic fatty liver disease (NAFLD) is a major cause of chronic liver disease in Gulf countries such as the Kingdom of Saudi Arabia (KSA), Bahrain, and the UAE in both the adult and pediatric population [27]. Although there are not many studies evaluating the prevalence of NAFLD in the region, available data suggest that the prevalence of NAFLD in the Middle East countries (32\%) is similar to worldwide incidence, with impactful consequence and disease burden [1]. The prevalence of NAFLD in Kuwait, South of Iran, and North of Iran was 33.3\%, 21.5\%, and 43.8\%, respectively [28,29], whereas a recent study conducted in 2018 indicated the prevalence to be estimated at 25\% in both KSA and UAE. 
By 2030 , the total NAFLD population is projected to increase to $48 \%$ in Saudi Arabia and $46 \%$ in UAE [26].

The increasing cases of NAFLD and Non-alcoholic Steatohepatitis (NASH) in this region can be attributed to the high prevalence of risk factors such as obesity, diabetes mellitus (DM), dyslipidaemia, and MetS [27]. According to data from the World Health Organization (WHO), obesity rates among adults are exceptionally high in the region, at more than 35\% in KSA, 37\% in the UAE, 32\% in Qatar, and almost 40\% in Kuwait [30]. The prevalence of MetS in the Middle East is estimated to be around 20-37\% [31]. Overweight, obesity, and diabetes mellitus are major components of MetS that negatively affect patient survival. The Middle East is ranked second by the International Diabetes Federation (IDF) for the incidence of diabetes, with an age-adjusted prevalence rate of $10.8 \%$ [32]. Diabetes is prevalent in over 1/6th of the total population in Kuwait (15.8\%), Bahrain (16.5\%), UAE $(17.3 \%)$, and Saudi Arabia (17.7\%). An increase in DM prevalence has been attributed to increasing urbanization, aging, obesity, reduced physical activity, and unhealthy diet [32].

In addition to the high prevalence of NAFLD, there is some evidence suggesting rising rates of adverse outcomes related to NAFLD and NASH in the region. In fact, NASH is currently considered to be the leading indication for liver transplantation in some gulf countries [26]. The consolidated data suggests that the disease burden associated with NAFLD and NASH in the Middle East region is on the rise; hence, there exists an urgent need for improving the diagnostic and management outcomes of patients.

\subsection{Diagnostic Scenario of NAFLD/NASH in the Middle East \\ 3.2.1. International Guideline Recommendations}

NAFLD is characterized by excessive hepatic fat accumulation, associated with insulin resistance (IR), and is defined by the presence of steatosis in $>5 \%$ of hepatocytes according to histological analysis, or by a proton density fat fraction $>5.6 \%$ assessed by proton magnetic resonance spectroscopy (1H-MRS) or quantitative fat/water selective magnetic resonance imaging (MRI). NASH is defined as the presence of $\geq 5 \%$ hepatic steatosis and inflammation with hepatocyte injury (e.g., ballooning), with or without any fibrosis [4,22].

The international guidelines recommend that the diagnosis of steatosis should lead to complete evaluation of family and personal history of NAFLD-associated diseases and the exclusion of secondary causes of steatosis with a careful assessment of alcohol intake. Furthermore, the daily alcohol consumption of $\geq 30 \mathrm{~g}$ for men and $\geq 20 \mathrm{~g}$ for women ( $>21$ standard drinks per week in men and >14 standard drinks per week in women) is considered a reasonable threshold for significant alcohol consumption when evaluating patients with suspected NAFLD. The detailed protocol of initial blood evaluations and extended evaluations recommended by EASL are presented in Table 1. Likewise, as the prevalence of NAFLD equates the prevalence of MetS and its components, increasing the risk of advanced disease, a thorough assessment of all components of MetS is recommended. Similarly, the occurrence of obesity/T2DM or elevated liver enzymes in patients with metabolic risk factors should prompt non-invasive screening to predict steatosis, NASH, and fibrosis. Non-invasive assessments help to identify the risk of NAFLD, in addition to monitoring disease progression and predicting the response of therapeutic interventions. This further aims to reduce the need for liver biopsy considering it is often limited by cost, sampling error, patient compliance, and procedure-related morbidity and mortality. NASH, however, is diagnosed by a liver biopsy presenting steatosis, hepatocyte ballooning, and lobular inflammation $[4,22,33]$. The guidelines also recommend calculating the surrogate markers of fibrosis (NFS, FIB-4, ELF, or FibroTest) in order to rule out significant fibrosis $(\geq F 2)$ in NAFLD patients. In patients for whom significant fibrosis cannot be ruled out, transient elastography/fibroscan should be conducted, and in cases of confirmed significant fibrosis the final diagnosis should be made by liver biopsy. A comprehensive CVD workup is recommended for all cases of NAFLD [4,22]. 
Table 1. European Association for the Study of the Liver (EASL), European Association for the Study of Diabetes (EASD) and European Association for the Study of Obesity (EASO): EASL-EASD-EASO clinical practice guidelines for the management of non-alcoholic fatty disease (NAFLD): protocol for a comprehensive evaluation of suspected NAFLD patients [4].

\begin{tabular}{|c|c|c|}
\hline Level & Variable & \\
\hline \multirow{9}{*}{$\begin{array}{c}\text { Initial } \\
\text { evaluation }\end{array}$} & 1 & Alcohol intake: <20 g/day (women), <30 g/day (men) \\
\hline & 2 & Personal and family history diabetes, hypertention and CVD \\
\hline & 3 & BMI, waist circumference, change in body weight \\
\hline & 4 & Hepatitis B/hepatitis C virus infection \\
\hline & 5 & History of steatosis-association drugs \\
\hline & 6 & Liver enzymes (ALT, AST, GGT) \\
\hline & 7 & Fasting blood glucose, HbA1c, OGTT, (fasting insulin $\{\mathrm{HOMA}-\mathrm{IR}\}$ ) \\
\hline & 8 & Complete blood count \\
\hline & 9 & Abdominal ultrasound \\
\hline \multirow{3}{*}{$\begin{array}{l}\text { Extended * } \\
\text { evaluation }\end{array}$} & 1 & Ferritin and transferrin saturation \\
\hline & 2 & Tests for coeliac and thyroid diseases, polycystic ovary syndrome \\
\hline & 3 & Tests for rare liver diseases (Wilson, autoimmune disease, AATD) \\
\hline
\end{tabular}

\subsubsection{Challenges in Diagnosing NAFLD and NASH in the Middle East}

A wide range of challenges persist in the diagnosis of liver disease in the Middle East. Diagnosis of the disease in lean patients is considered as a major challenge, with no robust explanation except for the fact that lean people present no clear signs of obesity even after consumption of foods high in carbohydrates. Gastroenterologists in the region are not formally trained to conduct abdominal ultrasonography, which can lead to subjective results prone to discrepancies. Furthermore, the biopsy is not a common practice in the region with only $\sim 10 \%$ of patients undergoing liver biopsies due to patient reluctance. Physicians in the region consider liver biopsy as a last resort and wait for 5 years post-diagnosis of elevated liver enzymes and no improvement with lifestyle modifications. It was notable that although fibroscan with controlled attenuation parameter (CAP) technique is a noninvasive, time- and cost-effective test compared to liver biopsy [34], it was validated mostly for viral hepatitis, a condition not associated with significant degree of liver steatosis. In NAFLD patients, results could be influenced by many factors and its accuracy jeopardized if $\mathrm{BMI} \geq 25$. Additionally, fibrosis seromarkers had low patient accessibility due to high price point and low-to-none insurance coverage.

Owing to these multiple challenges, it is acknowledged that there is an unmet need to improve diagnostic procedures for NAFLD and NASH capability in the region.

\subsection{Expert Panel Opinion on Diagnosis}

The authors opined to adapt the diagnostic tests recommended by the EASL guidelines to suit the unique needs of the Middle Eastern region. The literature review was carried out in a narrative approach. Although no formal consensus protocol was applied, the expert guidelines were established through a thorough consensus process of reiteration of inquiries and challenges until the panel reached a unanimous agreement.

Ferritin and transferrin saturation tests were not recommended, whereas it was worthwhile testing for coeliac and thyroid diseases, and polycystic ovary syndrome. It was significant to note that tests for rare liver diseases (Wilson, autoimmune disease) are seldom recommended in the region due to high cost and low insurance coverage. 
The authors consensually established a set of diagnostics that may aid an appropriate diagnosis of NAFLD by general practitioners to overcome the diagnostic challenges faced in the region (Table 2).

Table 2. Expert panel opinion on the diagnostic tests for suspected NAFLD patients to be conducted in the Middle East practice.

\begin{tabular}{|c|c|}
\hline & Diagnostic Tests \\
\hline 1. & Personal and family history diabetes, hypertention and CVD \\
\hline 2. & BMI, waist circumference, change in body weight \\
\hline 3. & History of steatosis-association drugs \\
\hline 4. & Alcohol intake ${ }^{*}:<20 \mathrm{~g} /$ day (women), $<30 \mathrm{~g} /$ day (men) \\
\hline 5. & Hepatitis B virus markers (HBsAg, anti-HBC and anti-HBS) /Hepatitis C virus antibody \\
\hline 6. & Total LFT Profile, synthetic \& enzymatic, INR \& Creatinine \\
\hline 7. & Complete blood count \\
\hline 8. & Lipid profile, HDL cholestrol, triacylglycerol, uric acid \\
\hline 9. & Fasting blood glucose, HbA1c, OGTT \\
\hline 10. & TSH \\
\hline 11. & Abdominal ultrasound \\
\hline 12. & Fibroscan/ARFI \\
\hline 13. & Biopsy is not necessary in standard case, only if clinically indicated \\
\hline
\end{tabular}

The following recommendations were provided for the above suggested diagnostic tests (Table 3):

- Personal and family history needs to be elaborated:

$\bigcirc \quad$ All patients with a history of diabetes, dyslipidaemia, and obesity should be screened for NAFLD.

- Clinical manifestation of active liver disease and liver failure should be included during physical examination.

- In addition to alcohol, patient history should include testing for use of other substances such as anabolic androgens, herbal unregistered medications, and food supplements.

- Occupational history could be incorporated as a part of personal history as certain occupations add to the risk factors of liver disease, especially if occupation involves exposure to high emission gases.

- $\quad$ Lipid profile tests should be conducted in the initial visits

- Rule out hepatitis B and C infections after alcohol analysis (in the sequence of tests) in all patients as the majority of them originally belong to countries with a high prevalence of hepatitis $C$ infection.

- Liver function tests (LFT) not being limited to testing liver enzymes only, in order to provide more clarity on the disease.

- Consistent deranged LFT values for more than 2-3 months should prompt the addition of autoimmune markers to rule out the presence of autoimmune diseases in selected cases, such as middle-aged women, hyperglobulinaemia, etc.

- Further tests should be conducted if liver enzymes remain elevated above normal for 6 months or more. 
- AST to ALT ratio of 2:1 or greater, particularly in the setting of an elevated $\gamma$ GT, could be used as a parameter to diagnose the disease as it is suggestive of alcoholic liver disease.

Table 3. Expert panel opinion on the management of patients with NAFLD.

\begin{tabular}{|c|c|c|}
\hline INITIAL VISIT & $\begin{array}{l}\text { FOLLOW-UP } \\
\text { (2-3 Months) }\end{array}$ & $\begin{array}{l}\text { FOLLOW-UP } \\
\text { ( } \geq 6 \text { Months) }\end{array}$ \\
\hline $\begin{array}{l}\text { Screening for metabolic risk factors (DM } \\
\text { dyslipidemia, obesity, hypertension) } \\
\text { - } \quad \text { Personal history } \\
\text { - } \quad \text { Family history }\end{array}$ & Monitoring metabolic risk factors & Monitoring metabolic risk factors \\
\hline $\begin{array}{c}\text { Physical examination } \\
\text { (clinical manifestation of active liver } \\
\text { disease \& liver failure) }\end{array}$ & $\begin{array}{c}\text { Physical examination } \\
\text { (clinical manifestation of active liver disease } \\
\& \text { liver failure) }\end{array}$ & $\begin{array}{c}\text { Physical examination } \\
\text { (clinical manifestation of active liver } \\
\text { disease \& liver failure) }\end{array}$ \\
\hline $\begin{array}{ll} & \text { Screening for other risk factors } \\
\text { - } & \text { Alcohol } \\
\text { - } & \text { Drugs } \\
\text { - } & \text { Occupational risks } \\
\text { - } & \text { Viral infections (HCV, HBV) }\end{array}$ & Monitoring metabolic risk factors & Monitoring metabolic risk factors \\
\hline $\begin{array}{l}\text { Blood exams } \\
\text { - } \quad \text { Lipid profile } \\
\text { - Liver function tests }\end{array}$ & $\begin{array}{l}\text { Blood exams } \\
\text { - } \quad \text { Lipid profile } \\
\text { - Liver function tests: if still out of normal } \\
\text { range, check for autoimmune diseases }\end{array}$ & $\begin{array}{l}\text { Blood exams } \\
\text { - } \quad \text { Lipid profile } \\
\text { - } \quad \text { Liver function tests: if still out of } \\
\text { normal range, consider further tests }\end{array}$ \\
\hline $\begin{array}{l}\text { Non-invasive tests } \\
\text { - } \quad \text { Ultrasonography/MRCP } \\
\text { - } \quad \text { Fibroscan (with CAP) }\end{array}$ & $\begin{array}{l}\text { Non-invasive tests } \\
\text { - } \quad \text { Ultrasonography } \\
\text { - } \quad \text { Fibroscan }\end{array}$ & $\begin{array}{l}\text { Non-invasive tests } \\
\text { - } \quad \text { Ultrasonography } \\
\text { - } \quad \text { Fibroscan }\end{array}$ \\
\hline
\end{tabular}

\subsection{Treatment Scenario of NASH/NAFLD in the Middle East}

\subsubsection{International Guideline Recommendations}

The management of NAFLD includes treating liver disease as well as the related metabolic comorbidities such as obesity, hyperlipidemia, insulin resistance (IR), and T2DM. As epidemiological evidence suggests a close association between unhealthy lifestyle and NAFLD, international guidelines recommend lifestyle modification of diet, exercise, and weight loss to treat all patients with NAFLD [4,22]. Modest weight loss indicated reduction in liver fat, improved hepatic IR, and resulted in NASH regression, with studies demonstrating a weight loss of $\geq 7 \%$ is associated with histological improvement $[4,22,34]$. The various scientific societies have established guidance statements for lifestyle modifications related to energy restriction (500-1000 calories/day), physical activity (150-200 min/week moderate intensity in 3-5 sessions), and reduced alcohol and fructose consumption [35].

Despite the recommendations, it is not easy to ensure behavior changes in patients, with evidence demonstrating that NAFLD patients have large variability in their readiness to change both their diet and physical activity. Actual long-term compliance of subjects with NAFLD to lifestyle intervention protocols is usually reported to be unsatisfactory, and reinforcing the "motivation to change" in these subjects seems to be a critical factor [36].

Currently, no drug is approved to treat NAFLD; however, several categories of drugs have been described, according to the physiopathological mechanisms of liver injury in NAFLD, including antioxidants and insulin sensitizers. The guidelines suggest the use of these drugs only in biopsy-proven NASH patients with significant fibrosis, with strong limitations and as off-label treatments. Nonetheless, patients with less severe disease, but at high risk of disease progression, could also be candidates for treatment. 
Insulin sensitizer pioglitazone improves liver histology in patients with and without T2DM, with biopsy-proven NASH. However, the safety and efficacy of this drug has not been evaluated in treating patients without histological confirmation.

Antioxidants such as Vitamin E administered at a daily dose of $800 \mathrm{IU} /$ day improve liver histology in nondiabetic adults with biopsy-proven NASH, and therefore may be considered for this patient population. However, until further data supporting its effectiveness become available, vitamin $\mathrm{E}$ is not recommended to treat NASH in diabetic patients, NAFLD without liver biopsy, NASH cirrhosis, or cryptogenic cirrhosis. Due to the lipophilicity of the drug, high doses of vitamin $\mathrm{E}$ are required in order to achieve the therapeutic effect. Different meta-analyses highlighted safety concerns of lipophilicity of the drug, which further increases in hemorrhagic stroke, prostate cancer, and all-cause mortality. Guidelines suggest that the risk/benefit profile should be carefully discussed with each patient before initiating therapy [4,22,37-39].

\subsubsection{Silymarin in the Treatment of Fatty Liver Disease}

Silymarin, an extract from the Silybum marianum (milk thistle) plant containing various flavonolignans (with silybin being the most abundant and the major active component), has been used over the past decade as a herbal remedy for treating various liver diseases [40]. Silybin displays poor water solubility due to its highly hydrophobic and non-ionizable chemical structure: this may have a great influence on its bioavailability, which can be improved by the presence of additional substances with a solubilizing character (e.g., other flavonoids) [41].

Data from human studies suggest that when a standardized formulation was administered orally, silymarin flavonolignans undergo rapid and extensive hepatic conjugative metabolism with primarily biliary excretion, after which silymarin enters an enterohepatic circulation. In fact, if on one hand silymarin unconjugated compounds had short halflives and low systemic exposures; on the other hand, the total silymarin flavonolignans (unconjugated + conjugated) achieved highest exposures as a result of the enterohepatic cycling - it is considered to be crucial for treatment effectiveness [41]. Furthermore, preclinical data evaluating bioavailability and physiological achievable level of silymarin in different tissue showed that the liver achieved the highest concentration, reflecting the presence of enterohepatic circulation and high epato-tropism [42].

Several pharmacological studies have been carried out on the active components of milk thistle, silymarin, and silibinin. It has been found that these substances exert hepatoprotective, antioxidant, anti-inflammatory, and anti-fibrotic properties. In addition, they stimulate protein biosynthesis and liver regeneration, increase lactation, and possess immuno-modulation activity [43]. The hepatoprotective and antioxidant properties of silymarin are due to its phenolic structure, by which it is able to form stable compounds with relevant biological reactive oxygen species that are produced from the hepatic metabolism of endogenous or exogenous toxic substances. Reactive oxygen species are known to damage cellular membranes and induce cell death. The release of cell contents and reactive oxygen species activate hepatic stellate cells, attracting hepatic macrophages that secrete pro-inflammatory and pro-fibrotic mediators, promoting an immune response and deposition of extracellular matrix, respectively [44]. This ultimately sustains the inflammatory and fibrotic status of the damaged liver. Silymarin is also documented to enhance hepatic glutathione and may contribute to the endogenous antioxidant defense of the liver [45].

Several clinical studies in NAFLD and liver damage caused by alcohol abuse or drug use, both in chronic or acute regimens, confirm that silymarin can positively impact liver disease progression and improve patients' symptomatology, clinical conditions, and quality of life $[24,26,46-51]$. Notably, silymarin treatment has been reported to effectively lower elevated liver enzymes levels in varying patient populations, including patients with NAFLD [24,49,50], NASH, or patients treated with potentially hepatotoxic drugs [46]. In addition, positive outcomes on metabolic endpoints have been reported in cases of metabolic/endogenous liver stress and in insulin resistance or diabetes [52,53]. Two recent 
studies conducted in non-cirrhotic patients with biopsy-proven NASH indicated that silymarin showed improvements in liver histopathologic findings of steatosis, inflammation and fibrosis, and reduction of liver stiffness measured by transient elastography [22,54]. An animal-model study of silymarin treatment during pregnancy and breastfeeding demonstrated no significant morpho-functional changes in offsprings, indicating safety of use during gestation and lactation [55]. Although silymarin has shown to inhibit certain drugmetabolizing enzymes and drug transporters (multidrug resistance-associated protein (MRP2) and breast cancer resistance protein (BCRP), such effects are unlikely to characterize in clinical settings [56]. Overall, silymarin is found to be safe, well-tolerated, and can be considered a beneficial treatment of NAFLD.

\subsubsection{Expert Panel Opinion on Treatment Regimen with Silymarin}

The authors opined that non-pharmacological therapies such as lifestyle modifications and diet are the cornerstone of NAFLD management, further governed by a multidisciplinary approach including psychologists, counsellors, and dieticians aimed at improving patient behaviour and motivation. The role of the clinicians was highlighted in counseling patients regarding the importance of maintaining a healthy diet and lifestyle. The involvement of family and caregivers was stated as an additional and important milestone toward successful outcomes.

In terms of pharmacological treatments, although no medications are currently approved for use by the international guidelines, the available medications are either limited to specific indications or have low safety profiles and inadequate safety/efficacy data in treating NAFLD. The benefits and safety of silymarin in treating NAFLD have been acknowledged by the authors, in virtue of its antioxidant, anti-inflammatory, and anti-fibrotic properties, aligning to initiate silymarin treatment as early as possible and continue as long as necessary. It was recommended to commence treatment as soon as an elevation in the liver enzymes was observed, and continue for a minimum of three months, after which a reassessment is recommended to verify effectiveness. Treatment was suggested to be continued for an additional three months post normalization of liver enzymes combined with monitoring at regular intervals (Figure 1). It was also recognized that positive lifestyle change supported by silymarin treatment had a synergistic effect and can further motivate the patient to stay on therapy. Finally, the combination of silymarin with other active compounds, such as vitamin E, would be beneficial to treat selected NAFLD/NASH cases.

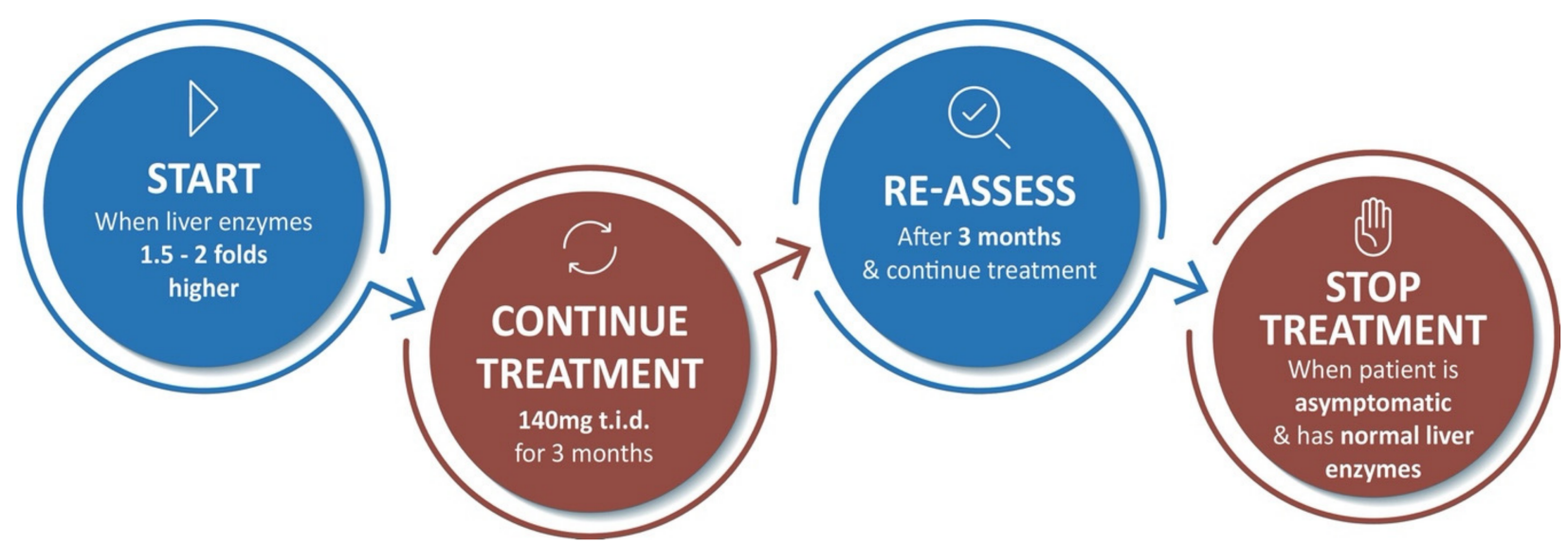

Figure 1. Expert panel opinion on the treatment regimen for silymarin. Start treatment with silymarin when patient's liver enzymes are elevated 1.5-2 folds higher than baseline. Continue treatment with $140 \mathrm{mg}$ silymarin thrice daily for three months, followed by reassessment of effectiveness for treatment continuation. Stop treatment when patient is asymptomatic and has returned to baseline liver enzymes. 


\section{Conclusions}

NAFLD remains the most common liver disease across the globe with increasing prevalence in the Middle East. This region encounters a range of diagnostic and treatment challenges, uncovering unmet needs to improve the management capability of NAFLD. Developing regional diagnostic procedures by adapting those recommended by EASL guidelines would help overcome the diagnostic challenges faced by the general physicians in this region, while easing the economic burden on patients. Although there is substantial evidence suggesting that silymarin treatment improves hepatic diseases, there is a need to educate patients on the use of silymarin to improve compliance. Although silymarin has demonstrated no effect on the course of pregnancy in animal models, caution is advised when administering silymarin to pregnant women as more studies with human models are required to precisely assess safety. Further clinical studies are required to investigate the impact of drug-drug interactions with silymarin.

Author Contributions: All authors have equal contributions for this work. All authors have read and agreed to the published version of the manuscript.

Funding: Conceptualization, methodology, analysis, and recommendations made in this paper were a group consensus initiated by the Authors of the Expert Panel. This was initiated by the literature review and cemented on the day the panel convened for an Expert Panel Advisory Board meeting. Financial support for all medical writing services and the Expert Panel Meeting was provided by Meda Pharma S.p.A, a Mylan Company. All authors have read and agreed to the published version of the manuscript.

Institutional Review Board Statement: Not applicable.

Informed Consent Statement: Not applicable.

Acknowledgments: The manuscript was developed as a consensus document by a team of experts in the fields of gastroenterology and hepatology in the Middle East. The consensus guidelines were elucidated at an advisory board meeting "Current hepatoprotective approach in the Middle East", held in Dubai, UAE in June 2019.

Conflicts of Interest: The authors declare no conflict of interest.

\section{References}

1. Younossi, Z.M.; Koenig, A.B.; Abdelatif, D.; Fazel, Y.; Henry, L.; Wymer, M. Global Epidemiology of Nonalcoholic Fatty Liver Disease-Meta-Analytic Assessment of Prevalence, Incidence and Outcomes. Hepatology 2016, 64, 73-84. [CrossRef]

2. Musso, G.; Gambino, R.; Cassader, M.; Pagano, G. A meta-analysis of randomized trials for the treatment of nonalcoholic fatty liver disease. Hepatology 2010, 52, 79-104. [CrossRef] [PubMed]

3. Perumpail, B.J.; Khan, M.A.; Yoo, E.R.; Cholankeril, G.; Kim, D.; Ahmed, A. Clinical epidemiology and disease burden of nonalcoholic fatty liver disease. World J. Gastroenterol. 2017, 23, 8263-8276. [CrossRef]

4. European Association for the Study of the Liver (EASL), European Association for the Study of Diabetes (EASD) and European Association for the Study of Obesity (EASO). EASL-EASD-EASO Clinical Practice Guidelines for the management of non-alcoholic fatty liver disease. J. Hepatol. 2016, 64, 1388-1402. [CrossRef]

5. Williams, C.D.; Stengel, J.; Asike, M.I.; Torres, D.M.; Shaw, J.; Contreras, M.; Landt, C.L.; Harrison, S.A. Prevalence of Nonalcoholic Fatty Liver Disease and Nonalcoholic Steatohepatitis Among a Largely Middle-Aged Population Utilizing Ultrasound and Liver Biopsy: A Prospective Study. Gastroenterology 2011, 140, 124-131. [CrossRef]

6. Yang, J.D.; Abdelmalek, M.F.; Pang, H.; Guy, C.D.; Smith, A.D.; Diehl, A.M.; Suzuki, A. Gender and menopause impact severity of fibrosis among patients with nonalcoholic steatohepatitis. Hepatology 2014, 59, 1406-1414. [CrossRef]

7. Browning, J.D.; Szczepaniak, L.S.; Dobbins, R.; Nuremberg, P.; Horton, J.D.; Cohen, J.C.; Grundy, S.M.; Hobbs, H.H. Prevalence of hepatic steatosis in an urban population in the United States: Impact of ethnicity. Hepatology 2004, 40, 1387-1395. [CrossRef]

8. Torres, D.M.; Williams, C.D.; Harrison, S.A. Features, Diagnosis, and Treatment of Nonalcoholic Fatty Liver Disease. Clin. Gastroenterol. Hepatol. 2012, 10, 837-858. [CrossRef]

9. Schwimmer, J.B.; Deutsch, R.; Kahen, T.E.; Lavine, J.; Stanley, C.; Behling, C. Prevalence of Fatty Liver in Children and Adolescents. Pediatrics 2006, 118, 1388-1393. [CrossRef] [PubMed]

10. Neuschwander-Tetri, A.B.; Loomba, R.; Sanyal, A.J.; Lavine, J.E.; Van Natta, M.L.; Abdelmalek, M.F.; Chalasani, N.; Dasarathy, S.; Diehl, A.M.; Hameed, B.; et al. Farnesoid X nuclear receptor ligand obeticholic acid for non-cirrhotic, non-alcoholic steatohepatitis (FLINT): A multicentre, randomised, placebo-controlled trial. Lancet 2015, 385, 956-965. [CrossRef] 
11. Marrero, J.A.; Fontana, R.J.; Su, G.I.; Conjeevaram, H.S.; Emick, D.M.; Lok, A.S. NAFLD may be a common underlying liver disease in patients with hepatocellular carcinoma in the United States. Hepatology 2002, 36, 1349-1354. [CrossRef]

12. Page, J.M.; Harrison, S.A. NASH and HCC. Clin. Liver Dis. 2009, 13, 631-647. [CrossRef] [PubMed]

13. Sanyal, A.; Poklepovic, A.; Moyneur, E.; Barghout, V. Population-based risk factors and resource utilization for HCC: US perspective. Curr. Med. Res. Opin. 2010, 26, 2183-2191. [CrossRef] [PubMed]

14. Agopian, V.G.; Kaldas, F.M.; Hong, J.C.; Whittaker, M.B.S.; Holt, C.; Rana, A.; Zarrinpar, A.D.; Petrowsky, H.; Farmer, D.; Yerzis, H.; et al. Liver transplantation for nonalcoholic steatohepatitis: The new epidemic. Ann. Surg. 2012, 256, 624-633. [CrossRef] [PubMed]

15. Vernon, G.; Baranova, A.; Younossi, Z.M. Systematic review: The epidemiology and natural history of non-alcoholic fatty liver disease and non-alcoholic steatohepatitis in adults. Aliment. Pharmacol. Ther. 2011, 34, 274-285. [CrossRef] [PubMed]

16. Li, Z.; Xue, J.; Chen, P.; Chen, L.; Yan, S.; Liu, L. Prevalence of nonalcoholic fatty liver disease in mainland of China: A meta-analysis of published studies. J. Gastroenterol. Hepatol. 2014, 29, 42-51. [CrossRef] [PubMed]

17. Ekstedt, M.; Hagström, H.; Nasr, P.; Fredrikson, M.; Stål, P.; Kechagias, S.; Hultcrantz, R. Fibrosis stage is the strongest predictor for disease-specific mortality in NAFLD after up to 33 years of follow-up. Hepatology 2015, 61, 1547-1554. [CrossRef] [PubMed]

18. Rafiq, N.; Bai, C.; Fang, Y.; Srishord, M.; Mc Cullough, A.; Gramlich, T.; Younossi, Z.M. Long-Term Follow-Up of Patients with Nonalcoholic Fatty Liver. Clin. Gastroenterol. Hepatol. 2009, 7, 234-238. [CrossRef]

19. Stepanova, M.; Rafiq, N.; Makhlouf, H.; Agrawal, R.; Kaur, I.; Younoszai, Z.; Mc Cullough, A.; Goodman, Z.; Younossi, Z.M. Predictors of All-Cause Mortality and Liver-Related Mortality in Patients with Non-Alcoholic Fatty Liver Disease (NAFLD). Dig. Dis. Sci. 2013, 58, 3017-3023. [CrossRef]

20. Golabi, P.; Otgonsuren, M.; De Avila, L.; Sayiner, M.; Rafiq, N.; Younossi, Z.M. Components of metabolic syndrome increase the risk of mortality in nonalcoholic fatty liver disease (NAFLD). Medicine 2018, 97, e0214. [CrossRef]

21. Chalasani, N.; Younossi, Z.; LaVine, J.E.; Charlton, M.; Cusi, K.; Rinella, M.; Harrison, S.A.; Brunt, E.M.; Sanyal, A.J. The diagnosis and management of nonalcoholic fatty liver disease: Practice guidance from the American Association for the Study of Liver Diseases. Hepatology 2018, 67, 328-357. [CrossRef]

22. Wah Kheong, C.; Mustapha, N.; Mahadeva, S. A Randomized Trial of Silymarin for the Treatment of Nonalcoholic Steatohepatitis. Clin. Gastroenterol. Hepatol. 2017, 15, 1940-1949. [CrossRef]

23. Gillessen, A.; Herrmann, W.A.; Kemper, M.; Morath, H.; Mann, K. Effect of silymarin on liver health and quality of life. Results of a non-interventional study. MMW Fortschr. Med 2014, 156, 120-126. [CrossRef]

24. Zhong, S.; Fan, Y.; Yan, Q.; Fan, X.; Wu, B.; Han, Y.; Zhang, Y.; Chen, Y.; Zhang, H.; Niu, J. The therapeutic effect of silymarin in the treatment of nonalcoholic fatty disease: A meta-analysis (PRISMA) of randomized control trials. Medicine 2017, 96 , e9061. [CrossRef] [PubMed]

25. Azizi, F.; Hadaegh, F.; Hosseinpanah, F.; Mirmiran, P.; Amouzegar, A.; Abdi, H.; Asghari, G.; Parizadeh, D.; Montazeri, S.A.; Lotfaliany, M.; et al. Metabolic health in the Middle East and North Africa. Lancet Diabetes Endocrinol. 2019, 7, 866-879. [CrossRef]

26. Alswat, K.; Aljumah, A.A.; Sanai, F.M.; Abaalkhail, F.; Alghamdi, M.; Al Hamoudi, W.K.; Al Khathlan, A.; Al Rifai, A.; Al Zaabi, M.; Babatin, M.A.; et al. Nonalcoholic fatty liver disease burden-Saudi Arabia and United Arab Emirates 2017-2030. Saudi J. Gastroenterol. 2018, 24, 211-219. [PubMed]

27. Kamal, S.; Aldossari, K.K.; Ghoraba, D.; Abdelhakam, S.M.; Kamal, A.H.; Bedewi, M.; Nabegh, L.; Bahnasy, K.; Hafez, T. Clinicopathological and immunological characteristics and outcome of concomitant coeliac disease and non-alcoholic fatty liver disease in adults: A large prospective longitudinal study. BMJ Open Gastroenterol. 2018, 5, e000150.

28. Ramezani-Binabaj, M.; Motalebi, M.; Karimi-Sari, H.; Rezaee-Zavareh, M.S.; Alavian, S.M.; Karimi-Sari, H. Are Women with Polycystic Ovarian Syndrome at a High Risk of Non-Alcoholic Fatty Liver Disease? A Meta-Analysis. Zahedan J. Res. Med. Sci. 2014, 14, e23235. [CrossRef]

29. Sohrabpour, A.; Rezvan, H.; Amini-Kafiabad, S.; Dayhim Merat, S.; Pourshams, A. Prevalence of Nonalcoholic Steatohepatitis in Iran: A Population based Study. Middle East J. Dig. Dis. 2010, 2, 14-19. [PubMed]

30. World Health Organization (WHO). Report on Non-Communicable Disease-Country Profiles. 2018. Available online: https: / /www.who.int/nmh/publications/ncd-profiles-2018/en (accessed on 28 January 2021).

31. Ansarimoghaddam, A.; Adineh, H.A.; Zareban, I.; Iranpour, S.; HosseinZadeh, A.; Kh, F. Prevalence of metabolic syndrome in Middle-East countries: Meta-analysis of cross-sectional studies. Diabetes Metab. Syndr. Clin. Res. Rev. 2018, 12, 195-201. [CrossRef]

32. International Diabetes Atlas. Chapter 3: Global Picture. Available online: https://idf.org/e-library/epidemiology-research/ diabetes-atlas.html (accessed on 28 January 2021).

33. World Gastroenterology Organisation Global Guidelines. Nonalcoholic Fatty Liver Disease and Nonalcoholic Steatohepatitis. 2012. Available online: https://www.worldgastroenterology.org/guidelines/global-guidelines/nafld-nash/nafld-nash-english (accessed on 28 January 2021).

34. Petersen, K.F.; Dufour, S.; Befroy, D.; Lehrke, M.; Hendler, R.E.; Shulman, G.I. Reversal of Nonalcoholic Hepatic Steatosis, Hepatic Insulin Resistance, and Hyperglycemia by Moderate Weight Reduction in Patients with Type 2 Diabetes. Diabetes 2005, 54, 603-608. [CrossRef]

35. Leoni, S.; Tovoli, F.; Napoli, L.; Serio, I.; Ferri, S.; Bolondi, L. Current guidelines for the management of non-alcoholic fatty liver disease: A systematic review with comparative analysis. World J. Gastroenterol. 2018, 24, 3361-3373. [CrossRef] [PubMed] 
36. Centis, E.; Moscatiello, S.; Bugianesi, E.; Bellentani, S.; Fracanzani, A.L.; Calugi, S.; Petta, S.; Grave, R.D.; Marchesini, G. Stage of change and motivation to healthier lifestyle in non-alcoholic fatty liver disease. J. Hepatol. 2013, 58, 771-777. [CrossRef]

37. Miller, E.R.; Pastor-Barriuso, R.; Dalal, D. Meta-analysis: High-dosage vitamin E supplementation may increase all-cause mortality. Ann. Intern. Med. 2005, 142, 37-46. [CrossRef] [PubMed]

38. Schürks, M.; Glynn, R.J.; Rist, P.M.; Tzourio, C.; Kurth, T. Effects of vitamin E on stroke subtypes: Meta-analysis of randomised controlled trials. BMJ 2010, 341, c5702. [CrossRef] [PubMed]

39. Klein, E.A.; Thompson, I.; Tangen, C.M.; Lucia, M.S.; Goodman, P.; Minasian, L.M.; Ford, L.G.; Parnes, H.L.; Gaziano, J.M.; Karp, D.D.; et al. Vitamin E and the risk of prostate cancer: Updated results of the Selenium and Vitamin E Cancer Prevention Trial (SELECT). J. Clin. Oncol. 2012, 30, 7. [CrossRef]

40. Surai, P.F. Silymarin as a Natural Antioxidant: An Overview of the Current Evidence and Perspectives. Antioxidants 2015, 4, 204-247. [CrossRef]

41. Bijak, M. Silybin, a Major Bioactive Component of Milk Thistle (Silybum marianum L. Gaernt.) —Chemistry, Bioavailability, and Metabolism. Molecules 2017, 22, 1942. [CrossRef] [PubMed]

42. Singh, R.P.; Tyagi, A.K.; Zhao, J.; Agarwal, R. Silymarin inhibits growth and causes regression of established skin tumors in SENCAR mice via modulation of mitogen-activated protein kinases and induction of apoptosis. Carcinogenesis 2002, 23, 499-510. [CrossRef] [PubMed]

43. Abenavoli, L.; Capasso, R.; Milic, N.; Capasso, F. Milk thistle in liver diseases: Past, present, future. Phytother. Res. 2010, 24, 1423-1432. [CrossRef]

44. Pellicoro, A.; Ramachandran, P.; Iredale, J.P.; Fallowfield, J.A. Liver fibrosis and repair: Immune regulation of wound healing in a solid organ. Nat. Rev. Immunol. 2014, 14, 181-944. [CrossRef]

45. Vargas-Mendoza, N.; Madrigal-Santillán, E.; Morales-González, A.; Esquivel-Soto, J.; Esquivel-Chirino, C.; García-Luna, M.; Rubio, R.; Gayosso de Lucio, J.A.; Morales-Gonzalez, J.A. Hepatoprotective effect of silymarin. World J. Hepatol. 2014, 6, 144-149. [CrossRef]

46. Solhi, H.; Ghahremani, R.; Kazemifar, A.M.; Yazdi, Z.H. Silymarin in treatment of non-alcoholic steatohepatitis: A randomized clinical trial. Casp. J. Intern. Med. 2014, 5, 9-12.

47. Saller, R.; Brignoli, R.; Melzer, J.; Meier, R. An Updated Systematic Review with Meta-Analysis for the Clinical Evidence of Silymarin. Forschende Komplementärmedizin/Res. Complement. Med. 2008, 15, 9-20. [CrossRef] [PubMed]

48. Tao, L.; Qu, X.; Zhang, Y.; Song, Y.; Zhang, S.-X. Prophylactic Therapy of Silymarin (Milk Thistle) on Antituberculosis DrugInduced Liver Injury: A Meta-Analysis of Randomized Controlled Trials. Can. J. Gastroenterol. Hepatol. 2019, 2019, 1-11. [CrossRef]

49. Hajiaghamohammadi, A.A.; Ziaee, A.; Oveisi, S.; Masroor, H. Effects of Metformin, Pioglitazone, and Silymarin Treatment on Non-Alcoholic Fatty Liver Disease: A Randomized Controlled Pilot Study. Hepat. Mon. 2012, 12, e6099. [CrossRef] [PubMed]

50. Hashemi, S.J.; Hajiani, E.; Sardabi, E.H. A placebo-controlled trial of silymarin in patients with nonalcoholic fatty liver disease. Hepat. Mon. 2009, 9, 265-270.

51. Loguercio, C.; Federico, A.; Trappoliere, M.; Tuccillo, C.; De Sio, I.; Di Leva, A.; Niosi, M.; D'Auria, M.V.; Capasso, R.; Blanco, C.D.V.; et al. The Effect of a Silybin-Vitamin E-Phospholipid Complex on Nonalcoholic Fatty Liver Disease: A Pilot Study. Dig. Dis. Sci. 2007, 52, 2387-2395. [CrossRef]

52. Velussi, M.; Cernigoi, A.M.; Ariella, D.M.; Dapas, F.; Caffau, C.; Zilli, M. Long-term (23 months) treatment with an antioxidant drug (silymarin) is effective on hyperinsulinemia, exogenous insulin need and malondialdehyde levels in cirrhotic diabetic patients. J. Hepatol. 1997, 26, 871-879. [CrossRef]

53. Huseini, H.F.; Larijani, B.; Heshmat, R.; Fakhrzadeh, H.; Radjabipour, B.; Toliat, T.; Raza, M. The efficacy of Silybum marianum (L.) Gaertn. (silymarin) in the treatment of type II diabetes: A randomized, double-blind, placebo-controlled, clinical trial. Phytother. Res. 2006, 20, 1036-1039. [CrossRef] [PubMed]

54. Navarro, V.J.; Belle, S.H.; D’Amato, M.; Adfhal, N.; Brunt, E.M.; Fried, M.W.; Reddy, K.R.; Wahed, A.S.; Harisson, S. Silymarin in NASH and C Hepatitis (SyNCH) Study Group. Silymarin in non-cirrhotics with non-alcoholic steatohepatitis: A randomized, double-blind, placebo controlled trial. PLOS ONE 2019, 14, e0221683.

55. Barbosa, C.C.; Nishimura, A.N.; Dos Santos, M.L.; Junior, W.D.; Andersen, M.L.; Mazaro-Costa, R. Silymarin administration during pregnancy and breastfeeding: Evaluation of initial development and adult behavior of mice. Neurotoxicology 2020, 78, 64-70. [CrossRef] [PubMed]

56. Xie, Y.; Zhang, Y.J. Metabolism, Transport and Drug-Drug Interactions of Silymarin. Molecules 2019, 24, 3693. [CrossRef] [PubMed] 